\section{Kidney Blood Pressure Research}

\title{
Oral Bicarbonate Slows Decline of Residual Renal Function in Peritoneal Dialysis Patients
}

\author{
Xiang-Yang Liu ${ }^{a} \quad$ Xiu-Mei Gao ${ }^{b} \quad$ Ning-Zhang ${ }^{c}$ Rui Chen ${ }^{a} \quad$ Feng $\mathrm{Wu}^{\mathrm{c}}$ \\ Xin-Chao Tao ${ }^{b}$ Chun-Jun Lid Ping Zhang ${ }^{b}$ Pei Yu
}

aDepartment of Diabetic Nephropathy Hemodialysis, Key Laboratory of Hormones and Development (Ministry of Health), Tianjin Key Laboratory of Metabolic Diseases, Tianjin Metabolic Diseases Hospital \& Tianjin Institute of Endocrinology, Tianjin Medical University; ${ }^{b}$ Department of Nephrology, Chinese PLA No. 254 Hospital; ' Department of Endocrinology, Chinese PLA No. 254 Hospital; dDepartment of Endocrinology, Key Laboratory of Hormones and Development (Ministry of Health), Tianjin Key Laboratory of Metabolic Diseases, Tianjin Metabolic Diseases Hospital \& Tianjin Institute of Endocrinology, Tianjin Medical Universtiy, China

\section{Key Words}

End-stage renal disease - Peritoneal dialysis - Continuous ambulatory peritoneal dialysis • Metabolic acidosis $\bullet$ Residual renal function
Abstract
Background/Aims: Metabolic acidosis is a common consequence of end-stage renal disease (ESRD) which may result in a substantial adverse outcome. The effect of oral bicarbonate on the preservation of residual renal function (RRF) in peritoneal dialysis (PD) patients has been rarely reported. Methods: We randomly assigned 40 continuous ambulatory peritoneal dialysis (CAPD) patients to the oral bicarbonate group or placebo group at a 1:1 ratio. All enrollments were followed for a duration of 104 weeks. We took residual creatinine clearance $(\mathrm{CCr})$, a measure of residual renal function (RRF), as the primary outcome. Residual $\mathrm{CCr}$ was calculated as the average of urea and creatinine clearance from a 24-hour urine collection. Results: Thirteen patients in the placebo group and 15 patients in the treatment group completed the 104 weeks of follow-up with a comparable dropout rate (placebo group: 35\% vs treatment group: $25 \%$ ). Compared with the placebo group, serum bicarbonate in treatment group was significantly increased at each time point, and oral bicarbonate resulted in a slower declining rate of residual $\mathrm{CCr}(\mathrm{F}=5.113, p=0.031)$. Baseline residual $\mathrm{CCr}$ at enrollment also had a significant effect on residual $\mathrm{CCr}(\mathrm{F}=168.779, P<0.001)$. Charlson Comorbidity Index which was adopted to calculate a comorbidity score had no significant effect on residual $\mathrm{CCr}$ loss ( $F=0.168, P=0.685)$. Conclusion: Oral bicarbonate may have a RRF preserving effect in CAPD patients, and a normal to high level of serum bicarbonate ( $\geq 24 \mathrm{mmol} / \mathrm{L})$ may be appropriate for RRF preservation.
X.-Y. Liu and X.-M. Gao contributed equally to this study and share first authorship. 


\section{Kidney Blood Pressure Research}

\section{Introduction}

Metabolic acidosis, which is mainly manifested as low serum bicarbonate, is common in end-stage renal disease (ESRD) and may result in a series of severe consequences including protein-wasting, inflammation, low serum albumin concentration, insulin resistance and bone disease [1-6]. Correction of acidosis is one of the primary purposes of renal replacement treatment. The National Kidney Foundation Disease Outcomes Quality Initiative (K/DOQI) guideline recommends that a bicarbonate supplement in chronic peritoneal dialysis (PD) patients with serum bicarbonate $<22 \mathrm{mmol} / \mathrm{L}$ is beneficial for bone metabolism and nutritional status [7]. However, the optimal level of serum bicarbonate or arterial $\mathrm{pH}$ needed to achieve the desired results is currently unknown $[8,9]$.

Decline of residual renal function (RRF) is an independent risk factor of adverse outcomes in chronic kidney disease (CKD) and ESRD patients $[10,11]$. Maiorca et al. reported a 50\% reduction in mortality of $P D$ patients with RRF, and every $1 \mathrm{ml} / \mathrm{min}$ increase in glomerular filtration rate was associated with a $40 \%$ reduction in the risk of death in dialysis patients [12]. Similarly, another prospective observational study also reported a strong association between RRF and PD patient survival [12-14]. Several factors such as age, sex, inflammatory/ nutritional status, peritonitis rate, blood pressure, hemoglobin, renal function and transport type at PD initiation, and ESRD etiology were all reported to be associated with the loss of RRF $[15,16]$. However, whether or not low serum bicarbonate has an impact on RRF in PD patient is unclear $[17,18]$. Some fundamental and clinical trials showed that base supplementation, either by modification of the diet or by bicarbonate administration, might slower the decline of kidney function in subjects with CKD [19-21]. A single-center randomized controlled study conducted by de Brito-Ashurst and his colleagues [22] in late stage CKD patients with acidosis demonstrated that correction of metabolic acidosis with alkali supplements slowed the progression of CKD to ESRD. Two other studies showed that alkali supplements, either sodium citrate or sodium bicarbonate, had a GFR preserving effect in CKD patients $[23,24]$. A meta-analysis concluded that alkali therapy might provide a long-term favorable effect on renal function in patients with CKD [25]. Nevertheless, rare study was conducted in peritoneal dialysis patients. Furthermore, does more active base supplementation therapy have a further renal function preserving effect in peritoneal dialysis patients? Therefore, the purpose of this study was to testify the hypothesis that maintenance of a normal to high level of serum bicarbonate by administration of oral bicarbonate may slow the decline of residual renal function in peritoneal dialysis patients.

\section{Patients and Methods}

\section{Patient selection}

This study was a single-center, randomized, placebo-controlled, double-blinded trial with a duration of 104 weeks. The trial was done in compliance with the protocols and principles of the Declaration of Helsinki and was approved by the Clinical Research Ethical Committee of Chinese PLA No. 254 Hospital. All patients have signed an informed consent before enrollment. Owing to the lack of similar studies, no minimal meaningful difference value and standard deviation of RRF have been reported. Therefore, sample size calculation could not be performed. We screened 168 ESRD patients who started PD in Chinese PLA No. 254 Hospital between June 2012 and December 2013. A total of 40 patients were recruited who met the following criteria: (1) under continuous ambulatory peritoneal dialysis (CAPD) for at least 6 months, and (2) stable clinical condition with serum bicarbonate $<24 \mathrm{mmol} / \mathrm{L}$ for at least two consecutive visits. Exclusion criteria: (1) < 18 years at the initiation of peritoneal dialysis; (2) history of hemodialysis (HD) or kidney transplantation; (3) initiation of PD for acute renal injury; (4) 24-hour urine output $<200 \mathrm{ml} /$ day; and (5) had oral bicarbonate within 2 weeks before the enrollment. We excluded patients who either were unlikely to survive or planned to have kidney transplant, or to transfer to other renal center within 6 months. 


\section{Kidney Blood Pressure Research} Kidney Blood Press Res 2017;42:565-574
\begin{tabular}{l|l}
\hline DOI: 10.1159/000479641 & C 2017 The Author(s). Published by S. Karger AG, Basel \\
Published onlIne: September 18, 2017 & www.karger.com/kbr
\end{tabular}

\section{Randomization and masking}

Patients were randomly assigned at a 1:1 ratio to receive either oral bicarbonate or placebo in a doubleblinded manner for 104 weeks. Random sequence was generated by computer, and the allocation programs were enclosed in coded, opaque, sealed envelopes. Both oral bicarbonate and placebo tablets (manufactured by Shanghai Yurui Biotechnology Pharmaceutical Co., Ltd.) had identical appearance, flavor, and package. Blinded to treatment allocation were study members such as nurses and patients, with exception of the designer and coordinator who initiated and distributed the tablets (oral bicarbonate or placebo). Patients in oral bicarbonate group were initiated at a dose of $1.0 \mathrm{~g} /$ day, with a recommendation of up-titration if serum bicarbonate was $<24 \mathrm{mmol} / \mathrm{L}$ and down-titration if serum bicarbonate was $>30 \mathrm{mmol} / \mathrm{L}$. Oral bicarbonate doses could be adjusted at any time of the follow-up period. Placebo was also initiated at a dose of $1.0 \mathrm{~g} / \mathrm{day}$, and was adjusted completely according to the oral bicarbonate dosage of the last patient in treatment group.

\section{Data collection}

Demographic and baseline clinical data were collected at the start of recruitment, which included age, gender, height, body weight, body mass index (BMI), systolic pressure, diastolic pressure, primary disease, and duration of PD. Comorbidity conditions were documented covering a comprehensive list of diseases, ranging from coronary artery disease, heart failure, peripheral vascular disease, cerebrovascular disease to dementia, chronic pulmonary disease, connective tissue disease, peptic ulcer disease, liver disease, diabetes with or without complications, and from hemiplegia, leukemia, solid tumor, malignancy to AIDS. A comorbidity score was calculated using the Charlson Comorbidity Index.

Patients were followed at week -4, 0, 2, 4, 8, 26, 52, 78 and 104. Patients received diet and lifestyle counseling at each visit starting from the beginning of the placebo run-in period. Except for the trial medication, routine treatments such as antihypertensive drugs, calcitriol and erythropoietin were administrated according to the clinical needs. All the patients were treated with regular CAPD, with a lactate concentration of $35 \mathrm{mmol} / \mathrm{L}$ and calcium concentration of $1.25 \mathrm{mmol} / \mathrm{L}$. Dialysis prescription was not changed unless there was evidence of underdialysis [26]. Trial medication tablets were counted by the investigators every month to calculate compliance. Various parameters were recorded during the followup visits at week $0,4,26,52,78$ and 104, including body weight, systolic pressure, diastolic pressure, presence of edema (score from 0 to $3+$ ), the number and reason for hospitalization, hemoglobin level, serum electrolytes, serum albumin, serum C-reactive protein (CRP), serum urea, serum cretinine, total weekly creatinine clearance (CCr) (adjusted by body surface), total weekly Kt/V urea, dialysis volume, PD ultrafiltration and residual CCr. We took residual CCr (a measures of RRF) as the primary outcome in this trial. Residual CCr was calculated as the average of urea and creatinine clearance from a 24-hour urine collection [27]. Residual CCr was considered null when urine output was $<200 \mathrm{~mL} / \mathrm{d}$. When a patient reached a residual CCr below this level for 2 successive time points, we defined the patient as anuric from the first time point of the 2 measurements [17]. Carbon dioxide combining power, which is considered as an indirect measure of serum bicarbonate concentration, was tested using an electrode-based method (UniCel DXC 800; Beckman Coulter, Inc, CA) at week 0, 2, 4, 8, 26, 52 and 78.

\section{Statistical analysis}

The demographic and baseline clinical characteristics of the participants were compared between groups by $t$-test for continuous variables, and chi-square test for categorical variables. An intention to treat analysis, including subjects who dropped out of the trial, was adopted to avoid the effects of dropout which may break the random assignment to the treatment groups in the study. Last observation carried forward (LOCF) method was used to replace missing data to diminish the different attrition rates between the groups [28]. Overall statistical comparisons between the two groups were performed by repeated measures ANOVA. The effect of oral bicarbonate on residual CCr changes was analyzed by linear mixed models(LMMs) using treatment group (oral bicarbonate or placebo), baseline residual CCr, Charlson Comorbidity Index and patient ID as the fixed effects, and time (baseline, 26 week, 52 week, 78 week and 104 week) as the random effect. Compound symmetry covariance structure was employed for the repeated factor of time. Additionally, we employed a LMM calculation in which only subjects in each group who started and completed the followups were included to improve the robustness and stability of our conclusion. An independent $t$-test was used to compare differences in the changes of hemoglobin level, serum bicarbonate, serum electrolytes, 


\section{Kidney Blood Pressure Research}

serum albumin, serum C-reactive protein (CRP), serum urea, serum cretinine, total weekly CCr (adjusted by body surface), total weekly Kt/V urea, dialysis volume, PD ultrafiltration and residual $\mathrm{CCr}$ between the two groups from 0 to 104 weeks. A $p$-value of $<0.05$ was considered statistically significant. All probabilities were two-tailed. Statistical analyses were performed by IBM SPSS Statistics, Version 18 for Windows (SPSS Inc, Chicago IL).

\section{Results}

Among the168 CAPD patients who were screened in our center for their eligibility of enrollment, 94 patients were ruled out owing to unwillingness to participate in the trial, and 32 patients were excluded due to the inability to meet the inclusion criteria. A total of 42 patients were randomly assigned, and

2 patients withdrew before trial started due to treatment preference. The full-analysis set consisted of 20 patients in placebo group and 20 patients in treatment group, and thus comprised the intention-to-treat group. While 13 patients in the placebo group completed the 104 weeks of follow-up, 15 patients in the treatment group completed the trial. Seven patients in the placebo group dropped out because of death $(n=2)$, skin rash $(n=1)$ and anuria $(n=4)$, and 5 patients in the treatment group withdrew because of death $(n=1)$, dyspepsia $(n=2)$ and anuria $(n=2)$. Flow of patients and reasons for withdrawal from the study are shown in Fig. 1.

The baseline clinical characteristics, laboratory findings, dialysis adequacy indices, residual GFR, and major comorbid conditions are shown in Table 1 . There was no significant difference in any baseline parameter between the two groups. The number of antihypertensive drugs between the two groups was not significantly different. Serum calcium and phosphorus in placebo and treatment group was $9.27 \pm 0.73$ versus $9.29 \pm 0.88 \mathrm{mg} /$ $\mathrm{dl}(p=0.93)$, and $5.49 \pm 0.82$ versus $5.52 \pm 0.85 \mathrm{mg} / \mathrm{dl}(p=0.94)$, respectively. Ten patients in placebo group and 9 in treatment group received calcium carbonate as phosphate binder. The average dose of calcium carbonate in placebo and treatment group was $1.60 \pm 0.26 \mathrm{~g} /$ day and $1.50 \pm 0.45 \mathrm{~g} /$ day, respectively $(p=0.57)$.

Serum bicarbonate levels during the follow-up are summarized in Fig. 2. The average dose of oral bicarbonate at each time point during the follow-up is shown in Table 2 . In the placebo group, there was a gradual but significant increase in serum bicarbonate level from $22.57 \pm 0.89 \mathrm{mmol} / \mathrm{L}$ to $24.12 \pm 0.97 \mathrm{mmol} / \mathrm{L}$ in week $4(P<0.01)$, which peaked at $26.82 \pm 0.82$ $\mathrm{mmol} / \mathrm{L}$ in week 8 , and then almost returned to the baseline level of $22.91 \pm 1.23 \mathrm{mmol} / \mathrm{L}$

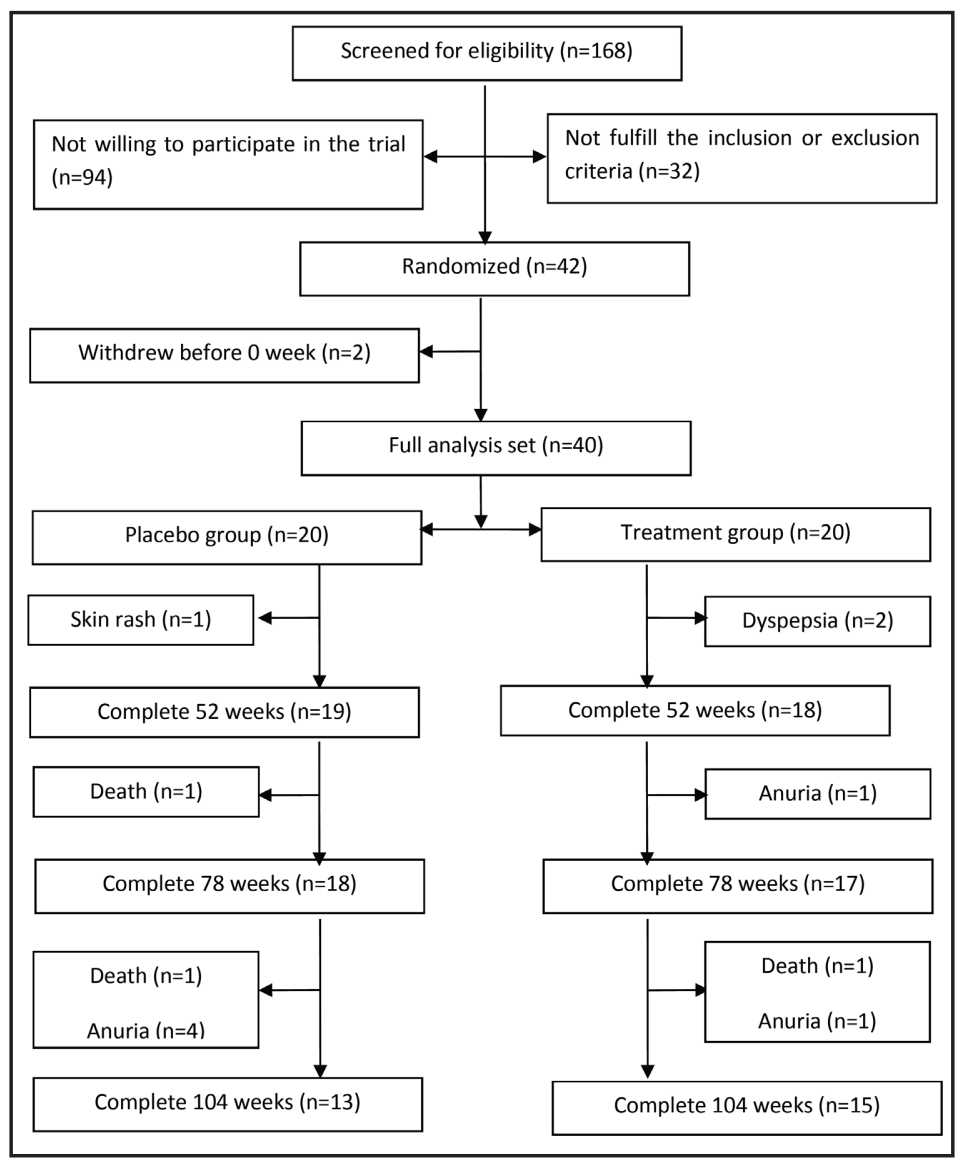

Fig. 1. Patients flow and and reasons for withdrawal. 


\section{Kidney \\ Blood Pressure \\ Research}

Table 1. Baseline characteristics of patients. Values for categorical variables are expressed as numbers; Values for continuous variables are expressed as mean \pm stan dard deviation. GFR, glomerular filtration rate; COPD chronic obstructive pulmonary d is e a s e s : AIDS, acquired immunodeficiency syndrome; CRP, C-reactive protein Note: There was no statistically significant difference between the two groups

\begin{tabular}{|c|c|c|}
\hline & Placebo Group & Treatment Group \\
\hline No. of patient & 20 & 20 \\
\hline Gender (M:F) & $10: 10$ & $10: 10$ \\
\hline Age (yr) & $56.20 \pm 13.58$ & $55.10 \pm 16.05$ \\
\hline Duration of dialysis (mo) & $44.60 \pm 24.68$ & $35.55 \pm 20.21$ \\
\hline Body height $(\mathrm{cm})$ & $163.25 \pm 8.58$ & $167.50 \pm 7.54$ \\
\hline Body weight (kg) & $64.59 \pm 12.17$ & $60.02 \pm 9.52$ \\
\hline Body surface area $\left(\mathrm{m}^{2}\right)$ & $1.8 \pm 0.2$ & $1.8 \pm 0.2$ \\
\hline Mean systolic pressure (mmHg) & $135 \pm 18$ & $137 \pm 19$ \\
\hline Mean diastolic pressure (mmHg) & $81 \pm 9$ & $82 \pm 9$ \\
\hline Urine volume $(\mathrm{ml} / 24 \mathrm{~h})$ & $780 \pm 261$ & $781 \pm 299$ \\
\hline \multicolumn{3}{|l|}{ Laboratory findings } \\
\hline Hemoglobin (g/dl) & $102.15 \pm 4.86$ & $101.05 \pm 7.44$ \\
\hline Serum albumin (g/dl) & $35.69 \pm 4.26$ & $36.34 \pm 3.48$ \\
\hline Serum bicarbonate $(\mathrm{mmol} / \mathrm{L})$ & $22.57 \pm 0.89$ & $22.43 \pm 0.97$ \\
\hline $\mathrm{CRP}(\mathrm{mg} / \mathrm{dl})$ & $0.23 \pm 0.30$ & $0.21 \pm 0.28$ \\
\hline Peritoneal ultrafiltration $(\mathrm{ml} / 24 \mathrm{~h})$ & $793.5 \pm 366.54$ & $720 \pm 438.48$ \\
\hline Total Kt/V & $1.90 \pm 0.20$ & $1.85 \pm 0.16$ \\
\hline Residual Kt/v & $0.36 \pm 0.15$ & $0.35 \pm 0.12$ \\
\hline Total GFR (ml/min/1.73m²) & $59.98 \pm 6.13$ & $59.83 \pm 7.50$ \\
\hline Residual GFR (ml/min) & $1.77 \pm 0.72$ & $1.63 \pm 0.63$ \\
\hline \multicolumn{3}{|l|}{ Primary disease (no. of cases) } \\
\hline Glomerulonephritis & 7 & 8 \\
\hline Diabetic Nephropathy & 6 & 5 \\
\hline Polycystic Kidney & 2 & 2 \\
\hline Hypertensive Nephropathy & 3 & 3 \\
\hline Other & 2 & 2 \\
\hline \multicolumn{3}{|l|}{ Major comorbidity (no. of cases) } \\
\hline Myocardial Infarction & 4 & 3 \\
\hline Congestive Heart Failure & 9 & 10 \\
\hline Peripheral Vascular Disease & 6 & 5 \\
\hline Cerebrovascular Disease & 4 & 7 \\
\hline Dementia & 0 & 0 \\
\hline COPD & 1 & 0 \\
\hline Connective Tissue Disease & 1 & 1 \\
\hline Peptic Ulcer Disease & 6 & 4 \\
\hline \multicolumn{3}{|l|}{ Diabetes Mellitus } \\
\hline 1 point uncomplicated, & 2 & 1 \\
\hline 2 points if end-organ damage & 6 & 5 \\
\hline \multicolumn{3}{|l|}{ Moderate to Severe Chronic } \\
\hline Kidney Disease (2 points)Hemiplegia (2 points) & 20 & 20 \\
\hline Leukemia (2 points) & 1 & 0 \\
\hline Malignant Lymphoma (2 point) & 0 & 0 \\
\hline Solid Tumor ( 2 points, 6 points if & 0 & 0 \\
\hline metastatic) & 0 & 0 \\
\hline Liver Disease ( 1 point mild, 3 points if moderate to severe) & 0 & 0 \\
\hline AIDS (6 points) & 0 & 0 \\
\hline Charlson Index Score & $4.35 \pm 1.46$ & $4.10 \pm 1.29$ \\
\hline
\end{tabular}

in week 104. In the treatment group, serum bicarbonate level rose dramatically from $22.43 \pm 0.97$ to $30.19 \pm 0.88 \mathrm{mmol} / \mathrm{L}$ after week $8(P<0.01)$. Although serum bicarbonate level of the treatment group gradually declined afterward, it remained significantly higher than that of the placebo group at each time point. Blood pressure and other parameters such as $\mathrm{Ca}^{2+}, \mathrm{P}$ and $\mathrm{K}^{+}$were also measured throughout the study (Table 2).

The baseline residual CCr, LMMs for repeated measures of time-by-group interactions and residual CCr calculated only from endogenous creatinine are all shown in Table 3.The baseline residual CCr was comparable between the two groups $(1.783 \pm 0.587$ vs $1.790 \pm 0.542$ $\mathrm{ml} / \mathrm{min}, p=0.29$ ). Residual CCr decreased through the 104 weeks in both groups. Although it 


\section{Kidney Blood Pressure Research}

Fig. 2. Serum bicarbonate levels (mmol/L) in treatment group (squares) and placebo group (triangles). Error bars denote SEM. ${ }^{*} P<0.01$ between treatment and placebo groups.

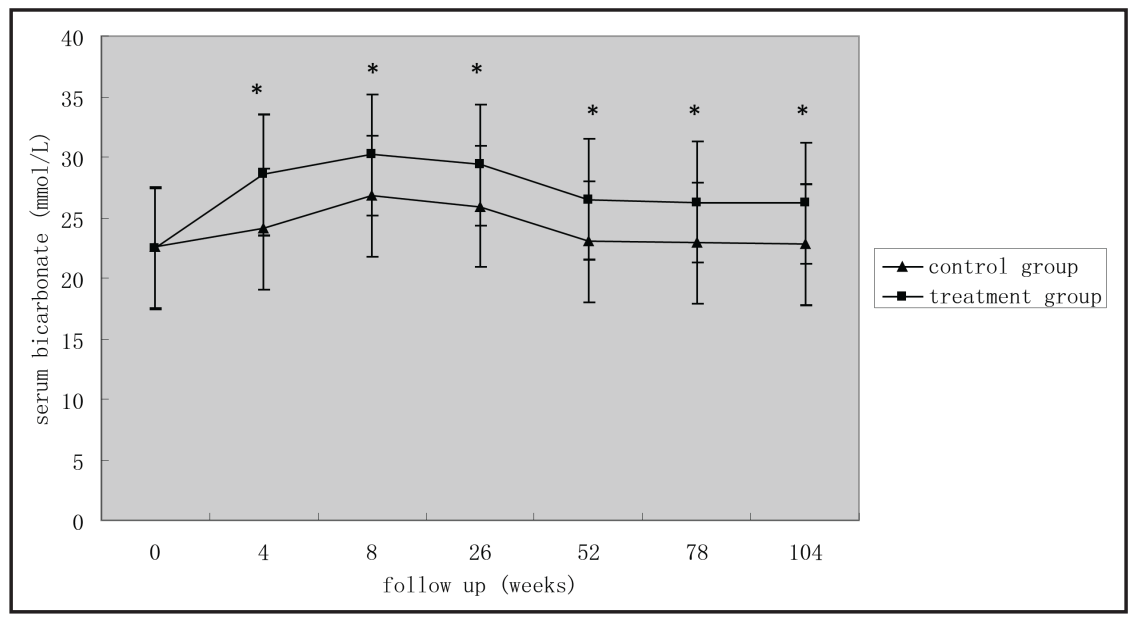

Table

2.

Dose of oral bicarbonate, blood pressure, serum $\mathrm{Ca}^{2+}, \mathrm{P}$ and $\mathrm{K}^{+}$throughout the follow-up

\begin{tabular}{lccccc}
\hline & Baseline & Week 26 & Week 52 & Week 78 & Week 104 \\
\hline $\begin{array}{l}\text { Dose of oral bicarbonate (g) } \\
\text { Mean systolic pressure (mmHg) }\end{array}$ & 1.0 & 1.5 & 1.5 & 1.5 & 1.5 \\
Placebo group & & & & & \\
Treatment group & $135 \pm 18$ & $137 \pm 16$ & $137 \pm 16$ & $136 \pm 16$ & $135 \pm 18$ \\
Mean diastolic pressure (mmHg) & & $137 \pm 18$ & $135 \pm 18$ & $137 \pm 16$ & $137 \pm 19$ \\
Placebo group & $81 \pm 9$ & $84 \pm 10$ & $81 \pm 11$ & $83 \pm 8$ & $83 \pm 8$ \\
Treatment group & $82 \pm 9$ & $83 \pm 8$ & $82 \pm 9$ & $83 \pm 9$ & $84 \pm 9$ \\
Serum Ca2+(mmol/L) & & & & & \\
Placebo group & $2.33 \pm 0.15$ & $2.40 \pm 0.12$ & $2.36 \pm 0.15$ & $2.37 \pm 0.12$ & $2.36 \pm 1.20$ \\
Treatment group & $2.32 \pm 0.17$ & $2.41 \pm 0.14$ & $2.35 \pm 0.13$ & $2.38 \pm 0.14$ & $2.37 \pm 0.13$ \\
Serum P (mmol/L) & & & & & \\
Placebo group & $1.67 \pm 0.12$ & $1.65 \pm 0.93$ & $1.66 \pm 0.11$ & $1.67 \pm 0.14$ & $1.66 \pm 0.11$ \\
Treatment group & $1.66 \pm 0.12$ & $1.66 \pm 0.12$ & $1.68 \pm 0.09$ & $1.67 \pm 0.14$ & $1.68 \pm 0.11$ \\
Serum K+ (mmol/L) & & & & & \\
Placebo group & $4.27 \pm 0.45$ & $4.29 \pm 0.55$ & $4.31 \pm 0.45$ & $4.21 \pm 0.37$ & $4.16 \pm 0.39$ \\
Treatment group & $4.24 \pm 0.41$ & $4.26 \pm 0.60$ & $4.30 \pm 0.49$ & $4.21 \pm 0.43$ & $4.17 \pm 0.34$ \\
\hline
\end{tabular}

Table 3. Baseline, 26-week follow-up, 52-week follow-up, 78-week follow-up, and 104-week follow-up outcome measures of patients in each group. * Calculated as (Clc+Clu)/2. ${ }^{* *}$ Calculated as Clc

\begin{tabular}{lcccccc}
\hline & Baseline & Week 26 & Week 52 & Week 78 & Week 104 & $P$ \\
\hline Total CCr (ml/min/1.73m²) & & & & & & \\
Placebogroup & $57.17 \pm 5.54$ & $56.97 \pm 8.20$ & $55.48 \pm 6.58$ & $53.89 \pm 4.92$ & $53.80 \pm 9.60$ & 0.91 \\
Treatment group & $55.89 \pm 6.99$ & $55.68 \pm 5.20$ & $54.37 \pm 4.99$ & $53.43 \pm 5.14$ & $53.00 \pm 8.44$ & \\
Residual CCr(ml/min)* & & & & & & \\
Placebo group & $1.78 \pm 0.59$ & $1.63 \pm 0.51$ & $1.32 \pm 0.48$ & $1.11 \pm 0.44$ & $1.00 \pm 0.48$ & \\
Treatment group & $1.79 \pm 0.54$ & $1.68 \pm 0.58$ & $1.50 \pm 0.56$ & $1.32 \pm 0.45$ & $1.24 \pm 0.47$ & 0.03 \\
Residual CCr(ml/min)** & & & & & & \\
Placebo group & $2.25 \pm 0.74$ & $2.20 \pm 0.51$ & $1.76 \pm 0.64$ & $1.52 \pm 0.61$ & $1.50 \pm 0.73$ & \\
Treatment group & $2.27 \pm 0.83$ & $2.29 \pm 0.58$ & $1.99 \pm 0.78$ & $1.78 \pm 0.60$ & $1.80 \pm 0.70$ & 0.04 \\
Total Kt/V & & & & & & \\
Placebo group & $1.83 \pm 0.20$ & $1.75 \pm 0.18$ & $1.74 \pm 0.18$ & $1.73 \pm 0.19$ & $1.71 \pm 0.22$ & 0.76 \\
Treatment group & $1.81 \pm 0.15$ & $1.74 \pm 0.14$ & $1.73 \pm 0.19$ & $1.71 \pm 0.13$ & $1.70 \pm 0.17$ & \\
\hline
\end{tabular}

seemed that residual CCr decreased at a faster rate in the placebo group than the treatment group starting at week 26, no significant difference was found between the two groups in each time point (for week $26,1.626 \pm 0.509$ vs $1.683 \pm 0.576 \mathrm{ml} / \mathrm{min}, p=0.742$; for week 52 , $1.331 \pm 0.483$ vs $1.503 \pm 0.556 \mathrm{ml} / \mathrm{min}, p=0.306$; for week $78,1.088 \pm 0.426$ vs $1.324 \pm 0.454$ $\mathrm{ml} / \mathrm{min}, p=0.098$; for week $104,0.985 \pm 0.468$ vs $1.241 \pm 0.471 \mathrm{ml} / \mathrm{min}, p=0.093$ ). Overall statistical comparisons by repeated measures ANOVA also showed a more rapid but 


\section{Kidney Blood Pressure Research}

insignificant decline of RRF in the placebo group ( $F=0.902, P=0.348$ ). LMMs for repeated measures showed a significant difference between placebo and oral bicarbonate groups $(\mathrm{F}=5.683, p=0.023)$. No significant interaction of group*time in RRF change was detected in our trial ( $\mathrm{F}=2.024, P=0.095)$. Time and baseline RRF also had significant effects on RRF change $(\mathrm{F}=42.365, P=0.000 ; \mathrm{F}=168.360, P=0.000$, respectively) but not on the Charlson Comorbidity Index score $(\mathrm{F}=0.163, P=0.689)$. Similar results were found when only subjects who completed the follow-up were included in the calculation (data not shown).

\section{Discussion}

Although high-lactate dialysate could improve nutritional status and reduce hospitalization of patients, it has limitations, such as the inability to adjust lactate concentration in dialysate when needed, and the possibility of alkalosis in some patients who extensively use high-lactate dialysate [29]. Citrate-based therapy was more effective on changes in serum calcium, magnesium and PTH [30], though more costly. Several observational studies have found that higher bicarbonate concentration may be associated with an improvement of kidney measures and survival for patients with CKD. For example, Kovesdy et al. reported lower CKD progression at bicarbonate concentrations of less than $28 \mathrm{mEq} / \mathrm{L}$ in veterans [31], and a similar conclusion was drew in AASK (African American Study of Kidney Disease and Hypertension) [32]. In our study, oral sodium bicarbonate was demonstrated as a convenient and safe method for correcting acidosis. In the treatment group, serum bicarbonate level reached its peak in week 8 , and then decreased gradually until the end of the study. Significant differences were found in all time points between the placebo and the bicarbonate groups. Interestingly, a transient elevation of serum bicarbonate in the placebo group was found during the first 8 weeks. We attributed this phenomenon to a "trial effect" which has been described in another study [33]. Diet and lifestyle counseling of the enrolled participants at each visit changed their diet and behavior and resulted in an increase of serum bicarbonate [33]. Moreover, the baseline therapy of calcium bicarbonate may have also influenced the level of serum bicarbonate. Increased serum $\left[\mathrm{HCO}_{3}\right]$ in the placebo patients might have been due to the short-term higher compliance with their previously prescribed $\mathrm{CaCO}_{3}$. After 8 weeks, gradual decline in serum bicarbonate level was detected in both groups, possibly due to the loss of RRF [33] and reduction in patients' compliance. This suggests that the addition of base-producing fruits and vegetables may transiently achieve the same outcome as oral bicarbonate, but the effect was not sustainable. At the same time, side effects such as hypercalcemia and ectopic calcification have limited the long-term usage of high dose calcium carbonate in the patients.

Endogenous creatinine clearance is an inaccurate determinant of the GFR because of the tubular secretion of creatinine. Urea clearance is lower than the inulin clearance because of the reabsorption of urea by the proximal tubules. Therefore, we adopted the mean of endogenous creatinine and urea clearance rate to approximate the RRF [34]. Our study showed that compared with placebo, oral administration of bicarbonate slowed down the rate of RRF decrease.

RRF plays an important role in maintaining fluid balance, phosphorus control, and removal of uremic toxins, and has a major impact on the outcome of PD [29, 35]. Metabolic acidosis is a common complication of CKD, and correction of acidosis is one of the primary purposes of renal replacement treatment. Our study showed that increasing serum bicarbonate to a relatively high level $(>24 \mathrm{mmol} / \mathrm{L})$ by oral administration of bicarbonate has a favorable effect on preserving RRF in PD patients. Although the underlying mechanism of metabolic acidosis in accelerating the deterioration of RRF in CKD patients is not clear, probable principles may involve endothelin, aldosterone, and angiotensin II caused by acid load [36-38]. Previous clinical studies had shown that oral carbonate or fruits and vegetables have a RRF-preserving effect during correction of metabolic acidosis [39, 40]. 


\section{Kidney Blood Pressure Research}

However, all of the above studies were conducted on participants in CKD stage 1-4 without dialysis, and the effect of oral bicarbonate on RRF in CAPD patients has not been reported. A 3-year observational study from Tae Ik Chang et al. [16] has reported that after adjusting for multiple potentially confounding covariates, the rate of RRF decline was significantly greater in patients with time-averaged serum bicarbonate $(\mathrm{TA}-\mathrm{Bic})<24 \mathrm{mEq} / \mathrm{L}$ than those with TA-Bic $>24 \mathrm{mEq} / \mathrm{L}$. In addition, patients with $\mathrm{TA}-\mathrm{Bic}<24 \mathrm{mEq} / \mathrm{L}$ also had a 2.62 -fold higher risk of becoming anuric. Nevertheless, whether correction of metabolic acidosis to the level of TA-Bic $>24 \mathrm{mEq} / \mathrm{L}$ provides additional protection for RRF in these patients is unknown. A randomized controlled trial which was aimed to detect the effect of oral bicarbonate on nutritional status and hospitalization of CAPD patients showed a tendency of slower decrease of RRF in the oral bicarbonate group [28]. Though, the absence of significant difference between the placebo and oral bicarbonate groups was probably due to the relative short follow-up.

Compared with previous studies, this study has several characteristics that strengthen the reliability of our findings. First, this is the first randomized controlled trial to our knowledge which was designed to investigate the effect of oral bicarbonate on RRF in CAPD patients. The random design guaranteed the balance of baseline characteristics of all participants and reduced bias from enrollment. Previous observational study only drew an association between oral bicarbonate and a decrease in RRF loss without determining the causal relationship. This interventional trial further examined the causality relationship and demonstrated that administrating oral bicarbonate and maintaining a normal to high level of serum bicarbonate may have a positive effect on RRF preservation. Second, the 104 weeks of follow-up time warranted the ability to detect the long-term effect of oral bicarbonate on RRF. As mentioned previously, a similar effect of oral bicarbonate was also detected in another trial [33], but because of its relative short observation period, no significant difference was detected between the two groups.

We acknowledge that there are some limitations in our study. First, the study was a single-center study which included only a small number of patients, but we increased the sample size by using repeated measures ANOVA. Large-scale prospective studies are required to further testify the conclusion. Second, the drop-out rate was high owing to the poor health condition and low baseline RRF of the enrolled patients [41], though we adopted the LMMs to take advantage of all the available data. Third, all the participants in our study accepted diet counseling at each visit, but protein intake and nutritional status were not assessed and was introduced to the analysis as a covariate. Modification of Diet in Renal Disease (MDRD) study has reported a potential benefit of dietary protein restriction to slow the progression of CKD [42]. Hence, diet protein intake and nutritional status should be taken into account in our subsequent studies. Fourth, patient-focused outcomes such as quality of life and physical function were not recorded, necessitating further research. At last, though we have found the causality between base supplement and the slowed decline of RRF, to what extent oral bicarbonate could decrease the mortality or morbidity of CAPD patients is still unknown. More long-term prognostic studies are required to answer this question.

\section{Conclusion}

Oral bicarbonate may have a RRF-preserving effect in CAPD patients, and an increase of serum bicarbonate to a normal or high level may slow the decline of RRF. Large-scale prospective studies are needed to confirm our findings.

\section{Disclosure Statement}

The authors declare that they have no conflicts of interest. 


\section{Kidney \\ Blood Pressure Research}

\section{Acknowledgments}

This work was sponsored by Tianjin healthcare industry under a key program (15KG101) and Tianjin science and technology support project (13ZCDSY01300).

\section{References}

1 Chiu YW, Kopple JD, Mehrotra R: Correction of metabolic acidosis to ameliorate wasting in chronic kidney disease: goals and strategies. Semin Nephrol 2009;29:67-74.

- Kalantar-Zadeh K, Mehrotra R, Fouque D, Kopple JD: Metabolic acidosis and malnutrition-inflammation complex syndrome in chronic renal failure. Semin Dial 2004;17:455-465.

-3 Ballmer PE, McNurlan MA, Hulter HN, Anderson SE, Garlick PJ, Krapf R: Chronic metabolic acidosis decreases albumin synthesis and induces negative nitrogen balance in humans. J Clin Invest 1995;95:3945.

4 Kopple JD, Kalantar-Zadeh K, Mehrotra R: Risks of chronic metabolic acidosis in patients with chronic kidney disease. Kidney Int Suppl 2005;S21-S27.

5 Kraut JA, Madias NE: Consequences and therapy of the metabolic acidosis of chronic kidney disease. Pediatr Nephrol 2011;26:19-28.

-6 Krieger NS, Frick KK, Bushinsky DA: Mechanism of acid-induced bone resorption. Curr Opin Nephrol Hypertens 2004;13:423-436.

7 Kopple JD: National kidney foundation k/doqi clinical practice guidelines for nutrition in chronic renal failure. Am J Kidney Dis 2001;37:S66-S70.

8 Wu DY, Shinaberger CS, Regidor DL, McAllister CJ, Kopple JD, Kalantar-Zadeh K: Association between serum bicarbonate and death in hemodialysis patients: is it better to be acidotic or alkalotic? Clin J Am Soc Nephrol 2006;1:70-78.

-9 Bommer J, Locatelli F, Satayathum S, Keen ML, Goodkin DA, Saito A, Akiba T, Port FK, Young EW: Association of predialysis serum bicarbonate levels with risk of mortality and hospitalization in the dialysis outcomes and practice patterns study (dopps). Am J Kidney Dis 2004;44:661-671.

10 Szeto CC, Wong TY, Chow KM, Leung CB, Law MC, Li PK: Independent effects of renal and peritoneal clearances on the mortality of peritoneal dialysis patients. Perit Dial Int 2004;24:58-64.

11 Vilar E, Farrington K: Emerging importance of residual renal function in end-stage renal failure. Semin Dial 2011;24:487-494.

12 Maiorca R, Brunori G, Zubani R, Cancarini GC, Manili L, Camerini C, Movilli E, Pola A, D'Avolio G, Gelatti U: Predictive value of dialysis adequacy and nutritional indices for mortality and morbidity in capd and hd patients. A longitudinal study. Nephrol Dial Transplant 1995;10:2295-2305.

13 Diaz-Buxo JA, Lowrie EG, Lew NL, Zhang SM, Zhu X, Lazarus JM: Associates of mortality among peritoneal dialysis patients with special reference to peritoneal transport rates and solute clearance. Am J Kidney Dis 1999;33:523-534.

14 Chung SH, Heimburger O, Stenvinkel P, Qureshi AR, Lindholm B: Association between residual renal function, inflammation and patient survival in new peritoneal dialysis patients. Nephrol Dial Transplant 2003;18:590-597.

15 Munguia-Miranda C, Ventura-Garcia MJ, Avila-Diaz M, Orihuela-Rodriguez O, Paniagua-Sierra JR: [factors related to residual renal function loss in patients in peritoneal dialysis]. Rev Med Inst Mex Seguro Soc 2015;53:578-583.

16 Coronel F, Perez FI: [factors related to loss of residual renal function in peritoneal dialysis]. Nefrologia 2008;28:S39-44.

17 Chang TI, Kang EW, Kim HW, Ryu GW, Park CH, Park JT, Yoo TH, Shin SK, Kang SW, Choi KH, Han DS, Han SH: Low serum bicarbonate predicts residual renal function loss in peritoneal dialysis patients. Medicine (Baltimore) 2015;94:e1276.

- 18 Chang TI, Oh HJ, Kang EW, Yoo TH, Shin SK, Kang SW, Choi KH, Han DS, Han SH: A low serum bicarbonate concentration as a risk factor for mortality in peritoneal dialysis patients. PLoS One 2013;8:e82912.

-19 Dobre M, Rahman M, Hostetter TH: Current status of bicarbonate in CKD. J Am Soc Nephrol 2015;26:515523. 


\section{Kidney \\ Blood Pressure Research}

Liu et al.: Bicarbonate Protects the Residual Renal Function in Peritoneal Dialysis

20 Gagg M, Sliber C, Sunder-Plassmann G: Effect of Oral Alkali Supplementation on Progression of Chronic Kidney Disease. Curr Hypertens Rev 2014;10:112-120.

21 Łoniewski I, Wesson DE: Bicarbonate therapy for prevention of chronic kidney disease progression. Kidney Int 2014;85:529-535.

22 de Brito-Ashurst I, Varagunam M, Raftery MJ, Yaqoob MM.: Bicarbonate supplementation slows progression of CKD and improves nutritional status. J Am Soc Nephrol 2009;20:2075-2084.

23 Phisitkul S, Khanna A, Simoni J, Broglio K, Sheather S, Rajab MH, Wesson DE: Amelioration of metabolic acidosis in patients with low GFR reduced kidney endothelin production and kidney injury, and better preserved GFR. Kidney Int 2010;77:617-623.

24 Mahajan A, Simoni J, Sheather SJ, Broglio KR, Rajab MH, Wesson DE: Daily oral sodium bicarbonate preserves glomerular filtration rate by slowing its decline in early hypertensive nephropathy. Kidney Int 2010;78:303-309.

25 Susantitaphong P, Sewaralthahab K, Balk EM, Jaber BL, Madias NE: Short- and long-term effects of alkali therapy in chronic kidney disease: a systematic review. Am J Nephrol 2012;35:540-547.

26 Szeto CC, Wong TY, Leung CB, Wang AY, Law MC, Lui SF, Li PK: Importance of dialysis adequacy in mortality and morbidity of chinese capd patients. Kidney Int 2000;58:400-407.

27 Nolph KD, Moore HL, Prowant B, Meyer M, Twardowski ZJ, Khanna R, Ponferrada L, Keshaviah P: Cross sectional assessment of weekly urea and creatinine clearances and indices of nutrition in continuous ambulatory peritoneal dialysis patients. Perit Dial Int 1993;13:178-183.

-28 Shao J, Jordan DC, Pritchett YL: Baseline observation carry forward: reasoning, properties, and practical issues. J Biopharm Stat 2009;19:672-684.

-29 Bargman JM, Thorpe KE, Churchill DN: Relative contribution of residual renal function and peritoneal clearance to adequacy of dialysis: a reanalysis of the canusa study. J Am Soc Nephrol 2001;12:2158-2162.

- 30 Šafránek R, Moučka P, Vávrová J, Palička V, Pavlíková L, Sulková SD: Changes of serum calcium, magnesium and parathyroid hormone induced by hemodialysis with citrate-enriched dialysis solution. Kidney Blood Press Res 2015;40:13-21.

- 31 Kovesdy CP, Anderson JE, Kalantar-Zadeh K: Association of serum bicarbonate levels with mortality in patients with nondialysis-dependent CKD. Nephrol Dial Transplant 2009;24:1232-1237.

-32 Raphael K, Wei G, Baird B, Greene T, Beddhu S: Higher serum bicarbonate levels within the normal range are associated with better survival and renal outcomes in African Americans. Kidney Int 2011;79:356-362.

-33 Szeto CC, Wong TY, Chow KM, Leung CB, Li PK: Oral sodium bicarbonate for the treatment of metabolic acidosis in peritoneal dialysis patients: a randomized placebo-control trial. J Am Soc Nephrol 2003;14:2119-2126.

34 Clinical practice guidelines for peritoneal dialysis adequacy. Am J Kidney Dis 2006;48:S98-S129.

-35 Shemin D, Bostom AG, Lambert C, Hill C, Kitsen J, Kliger AS: Residual renal function in a large cohort of peritoneal dialysis patients: change over time, impact on mortality and nutrition. Perit Dial Int 2000;20:439-444.

-36 Wesson DE, Simoni J: Acid retention during kidney failure induces endothelin and aldosterone production which lead to progressive gfr decline, a situation ameliorated by alkali diet. Kidney Int 2010;78:1128-1135.

37 Wesson DE, Jo CH, Simoni J: Angiotensin ii receptors mediate increased distal nephron acidification caused by acid retention. Kidney Int 2012;82:1184-1194.

-38 Phisitkul S, Hacker C, Simoni J, Tran RM, Wesson DE: Dietary protein causes a decline in the glomerular filtration rate of the remnant kidney mediated by metabolic acidosis and endothelin receptors. Kidney Int 2008;73:192-199.

-39 de Brito-Ashurst I, Varagunam M, Raftery MJ, Yaqoob MM: Bicarbonate supplementation slows progression of ckd and improves nutritional status. J Am Soc Nephrol 2009;20:2075-2084.

40 Goraya N, Simoni J, Jo C, Wesson DE: Dietary acid reduction with fruits and vegetables or bicarbonate attenuates kidney injury in patients with a moderately reduced glomerular filtration rate due to hypertensive nephropathy. Kidney Int 2012;81:86-93.

-41 Moher D, Schulz KF, Altman DG: The consort statement: revised recommendations for improving the quality of reports of parallel-group randomized trials. Ann Intern Med 2001;134:657-662.

42 Klahr S, Levey AS, Beck GJ, Caggiula AW, Hunsicker L, Kusek JW, Striker G: The effects of dietary protein restriction and blood-pressure control on the progression of chronic renal disease. Modification of diet in renal disease study group. N Engl J Med 1994;330:877-884. 